\title{
A fresh look at the glacial Arctic Ocean
}

\author{
WALTER GEIBERT ${ }^{1}$, JENS MATTHIESSEN ${ }^{2}$, INGRID \\ STIMAC $^{2}$, JUTTA WOLLENBURG ${ }^{2}$ AND RÜDIGER \\ STEIN $^{2,3}$
}

${ }^{1}$ Alfred Wegener Institut

${ }^{2}$ Alfred Wegener Institute

${ }^{3}$ MARUM - Center for Marine Environmental Sciences and Faculty of Geosciences, University of Bremen

Presenting Author: walter.geibert@awi.de

The seafloor morphology of the Arctic Ocean and the Nordic Seas show specific capped structures in water depths of up to $1000 \mathrm{~m}$. Together with modelling results, they strongly point to the existence of ice shelves covering the interior of the Arctic Ocean in past glacials[1,2]. In an attempt to link these major events to the sedimentary archive, we study a selection of new and existing data from many parts of the Arctic Ocean. We present activities of ${ }^{230} \mathrm{Th}$ together with ${ }^{234} \mathrm{U} /{ }^{238} \mathrm{U}$ ratios, the concentrations of manganese, sulphur and calcium in the context of lithological information, and we show records of microfossils and their isotope composition. New high resolution analyses (PS51/038, PS72/396) and a re-analysis of existing marine sediment records (PS1533, PS1235, PS2185, PS2200, amongst others) in view of the naturally occurring radionuclide ${ }^{230} \mathrm{Th}_{\mathrm{ex}}$ and, where available, ${ }^{10} \mathrm{Be}$ from the Arctic Ocean and the Nordic Seas reveal the widespread occurrence of intervals that are best explained by the temporary absence of sea water. [3].

We present a scenario of glacial conditions in which Bering Strait is closed and the Greenland-Scotland Ridge partly blocked by ice, leading to an accumulation of freshwater in liquid and solid form in the Arctic. This would explain how floating Arctic ice sheets, together with eustatic sea-level changes, have affected the past situation of the Arctic Ocean in a fundamental way that must have led to a drastic and non-linear response to certain threshold values, in agreement with sudden events in the climate record that were missing plausible explanations so far.

This concept can reconcile contrasting age models for the Late Pleistocene in the Arctic Ocean. Our view, if adopted, would allow a coherent dating approach across the Arctic Ocean and the Nordic Seas, also offering a new perspective on climate records from lower latitudes.

[1] Jakobsson, Nilsson, Anderson, Backman, Björk, Cronin, et al. (2016). Nature communications, 7(1), 10365.

[2] Gasson, DeConto, Pollard, Clark (2018). Nature communications, 9(1), 1510.

[3] Geibert, Matthiessen, Stimac, Wollenburg, Stein (2021). Nature, 590(7844), 97-102. 